\title{
Prognostic values of the inhibitor of DNA-binding family members in breast cancer
}

\author{
XIAO-LING ZHOU ${ }^{1 *}$, DE ZENG $^{2 *}$, YAN-HONG YE ${ }^{3}$, SHU-MING SUN ${ }^{3}$, XIAO-FENG LU ${ }^{3}$, \\ WEI-QUAN LIANG ${ }^{3}$, CHUN-FA CHEN ${ }^{3}$ and HAO-YU LIN ${ }^{3}$ \\ ${ }^{1}$ Department of Gynecology and Obstetrics, The First Affiliated Hospital of Shantou University Medical College; \\ ${ }^{2}$ Department of Medical Oncology, The Cancer Hospital of Shantou University Medical College; \\ ${ }^{3}$ Department of Thyroid and Breast Surgery, The First Affiliated Hospital of Shantou \\ University Medical College, Shantou, Guangdong 515000, P.R. China
}

Received March 12, 2018; Accepted July 17, 2018

DOI: 10.3892/or.2018.6589

\begin{abstract}
The inhibitor of DNA-binding (ID) proteins are dominant-negative modulators of transcription factors with basic helix-loop-helix (bHLH) structures, which control a variety of genes in cell cycle regulation. An increasing volume of evidence has demonstrated that the deregulated expression of IDs in several types of malignancy, including breast carcinoma, has been proven to serve crucial regulatory functions in tumorigenesis and the development of breast cancer (BC). The present study evaluated the prognostic values of the ID family members by investigating a set of publicly accessible databases, including Oncomine, bc-GenExMiner, Kaplan-Meier plotter and the Human Protein Atlas. The results demonstrated that mRNA levels of distinct IDs exhibited diverse profiles between $\mathrm{BC}$ and normal counterparts. The mRNA expression level of ID2 was significantly higher in breast cancer than normal tissues, while the mRNA expression levels of ID1, ID3 and ID4 were significantly lower in breast cancer tissues than in normal tissues. Furthermore, higher mRNA expression levels of ID1 and ID4 were associated with subgroups with lower pathological grades and fewer lymph node metastases. Survival analysis revealed that elevated mRNA levels of ID1 and ID4 predicted an improved survival in all patients with BC. Increased ID1 mRNA levels were associated with higher relapse-free survival rates in all patients with $\mathrm{BC}$, particularly in those with ER positive and Luminal A subtype tumors. Increased ID4 mRNA expression predicted longer survival
\end{abstract}

Correspondence to: Dr Hao-Yu Lin, Department of Thyroid and Breast Surgery, The First Affiliated Hospital of Shantou University Medical College (SUMC), 57 Changping Road, Shantou, Guangdong 515000, P.R. China

E-mail: rainlhy@stu.edu.cn

*Contributed equally

Key words: breast carcinoma, inhibitor of DNA binding, prognostic values times in all patients with BC, particularly in those with hormone receptor-positive tumors or those treated with endocrine therapy. These results indicated that IDs are essential prognostic indicators in BC. Future studies on the effect of IDs on the pathogenesis and development of $\mathrm{BC}$ are warranted.

\section{Introduction}

The inhibitor of DNA binding/differentiation (ID) proteins, as a group of helix-loop-helix transcription factors, are individually fundamental to development and cell cycle control (1). Recently, loss- and gain-of-function studies have indicated the oncogenic effects of ID proteins in tumors, and have revealed associations between these proteins and malignant features, including transformative cellular phenotype, abnormal senility, facilitating proliferation and distant spreading (2-4).

Different human malignancies have been detected for ID expression levels (5). For instance, it has been reported and agreed that increased levels of IDs were associated with malignant grade and a poor prognosis in various types of carcinoma (6-9). It has been revealed that increasing ID1 mRNA expression was observed in subtypes of human breast tumors and that this acted as a driver in BC metastasis (10-12). The extracellular micro-environmental signals can promote a role for ID2 in tumorigenesis (12-14). Overexpression of ID2 is associated with adverse outcomes in pancreatic carcinoma, neuroblastoma and pulmonary carcinoma (15-17). In addition, increased ID2 protein levels indicated an unfavorable prognosis in patients with basal-like subtypes of BC (18). Cellular localization of ID2 has been recognized as an important factor in determining disease outcome. In BC, cytoplasmic, but not nuclear, localization of ID2 protein was associated with less invasive and expansionary phenotypes $(19,20)$. Kowanetz et al demonstrated that abnormal ID2 or ID3 expression led to proliferation inhibition and epithelial-mesenchymal transition of BC cells, which was induced by transforming growth factor $\beta$. Furthermore, knockdown of endogenic ID2 or ID3 enhanced the sensitivity of breast epithelial cells to bone morphogenetic proteins (BMPs), which resulted in growth inhibition and poorer differentiation (21). Wen et al (22) reported the amplified ID4 protein in triple-negative breast carcinoma, while a 
study undertaken by Thike et al (23) demonstrated that ID4 may be downregulated by BRCA1.

Nonetheless, the specific roles of individual ID family members in $\mathrm{BC}$ and the association between IDs and the clinicopathological features of $\mathrm{BC}$ have not yet been elucidated. Therefore, in-depth investigation and analysis into the potential roles of ID proteins in $\mathrm{BC}$ is required, and may provide an insight into the molecular mechanisms underpinning the disease.

The present study aimed to systemically investigate the prognostic values and potential roles of individual IDs in BC based on a series of large databases. Characterization of the ID expression status of patients with BC may be valuable, not only for diagnostic and prognostic assessment, but also for guiding $\mathrm{BC}$ management in the future.

\section{Materials and methods}

Oncomine analysis. In order to analyze the expression levels of specific IDs in a variety of malignancies, an access online database Oncomine (www.oncomine.org), which is an online cancer microarray database to facilitate and promote discovery from genome-wide expression analyses, was used. Paired Student's t-test was used, and a fold-change of 2 with a P-value of $<0.01$ was defined as clinically significant, as previously described (24).

Breast cancer gene-expression miner $v 4.0$ analysis. In order to analyze the association among expression levels of specific IDs and specific clinicopathological features of $\mathrm{BC}$, including hormonal receptors and lymph nodal status, the open access database Breast Cancer Gene-Expression Miner v4.0 (bcGenExMiner v4.0), which is comprised of 36 annotated genomic datasets and three statistical mining functions, was used (http://bcgenex.centregauducheau. fr/BC-GEM/GEM-requete.php) $(25,26)$.

GOBO analysis. The mRNA expression levels of IDs were analyzed by uploading corresponding affymetrix probes to the $G O B O$ database (http://co.bmc.lu.se/gobo/gsa.pl). $G O B O$ is an online accessible tool that allows rapid evaluation of gene expression levels, identification of co-expressed genes and connection with prognosis for single gene, gene sets or gene signatures in a BC dataset.

The human protein atlas. The Human Protein Atlas (HPA) is an open access program that maps all the human proteins in cells, as well as tissue samples (https://www.proteinatlas.org/) (27). The Pathology Atlas of HPA demonstrates the association between specific protein levels and survival of patients with BC (28).

The Kaplan-Meier plotter survival analysis. To analyze the prognostic values of specific IDs in BC samples, the Kaplan-Meier plotter (www.kmplot.com) was used to display the relapse-free survival (RFS). The log-rank P-value was presented on the webpage (29).

\section{Results}

mRNA expression patterns of ID family members in human $B C$. Thus far, four ID family members have been identified

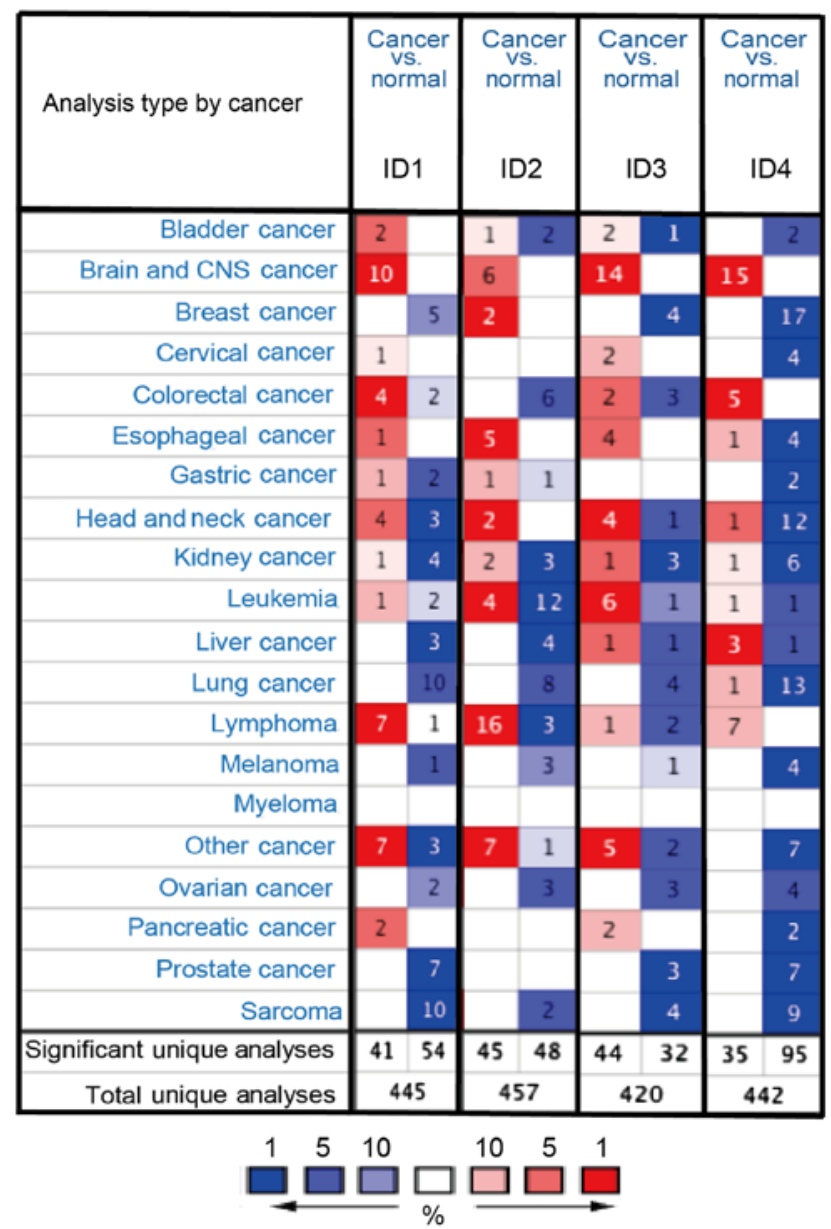

Figure 1. mRNA expression patterns of the ID family members in different types of human cancer. The mRNA expression of ID family members (cancer vs. normal tissue) analyzed with Oncomine database. The graphic demonstrated the numbers of datasets with statistically significant mRNA overexpression (red) or downregulated expression (blue) of the target gene. The P-value threshold was 0.01 . The number in each cell represented the number of analyses that meet the threshold within those analysis and cancer types. The gene rank was analyzed by percentile of the target gene in the top of all genes measured in each research. Cell color was determined by the best gene rank percentile for the analyses within the cell. The P-value was set up at 0.01 and fold-change was defined as 2 .

in human cancer. The differences in the mRNA expression of the 4 IDs between tumor and normal tissues in multiple types of cancer were analyzed using the online Oncomine database. As demonstrated in Fig. 1, the Oncomine database contained a total of 445, 457, 420 and 442 unique analyses for ID1, ID2, ID3 and ID4, respectively. In BC analysis, there were two studies revealing a statistically significant increase in the mRNA expression level of ID2 in BC tissues, compared with normal tissues. As for ID1, ID3 and ID4, five, four and 17 unique analyses datasets with statistical significance revealed higher expression levels in normal tissues than in cancer tissues. These data indicated that the expression of ID1, ID3 and ID4 was markedly lower in BC samples than in normal breast tissues (Fig. 1).

We also analyzed gene alterations using CbioPORTAL. Based on the analysis of CbioPORTAL, the genetic alteration rate of ID1-ID4 was 2.2, 2.1, 0.5, and 2.8\%, respectively. However, there was no significant association between gene alteration and without alteration (data not shown). 
A

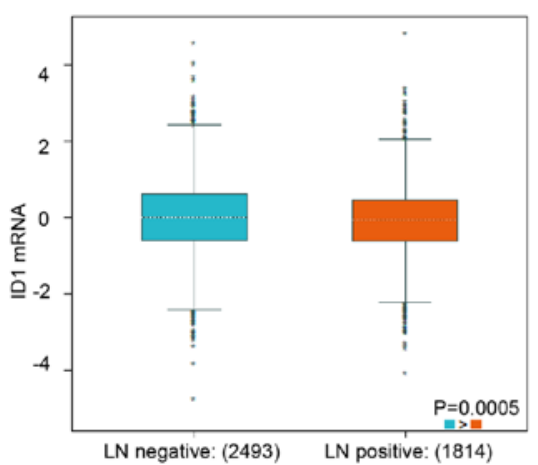

C

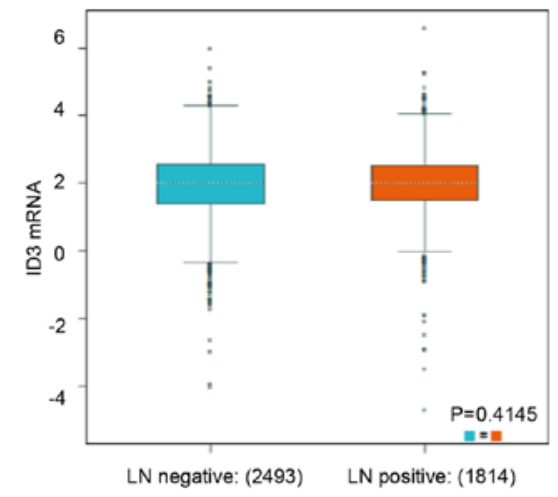

E

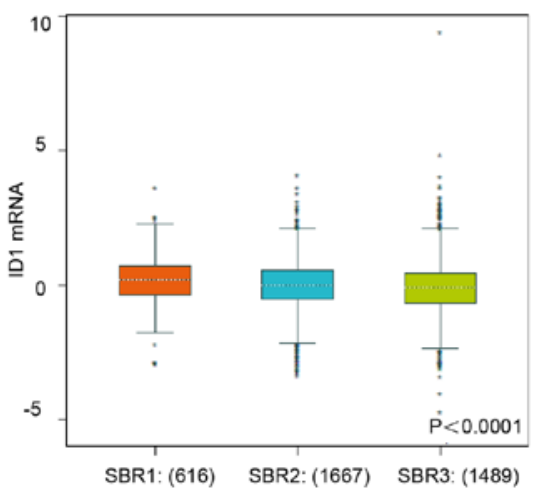

G

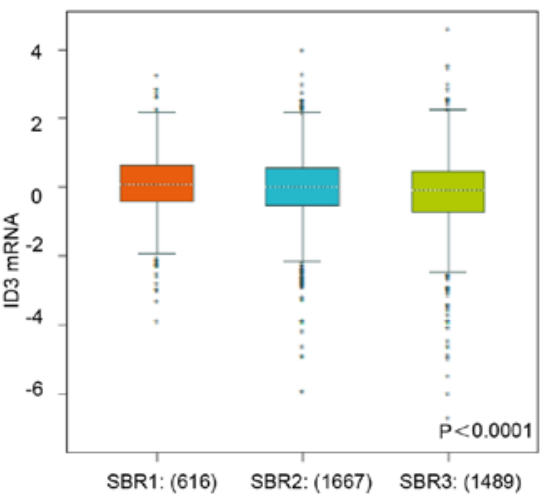

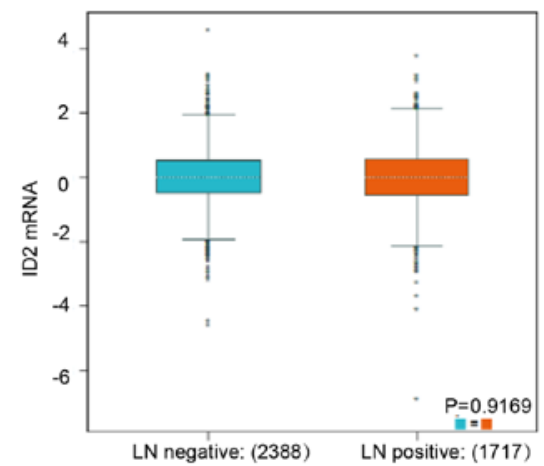

D

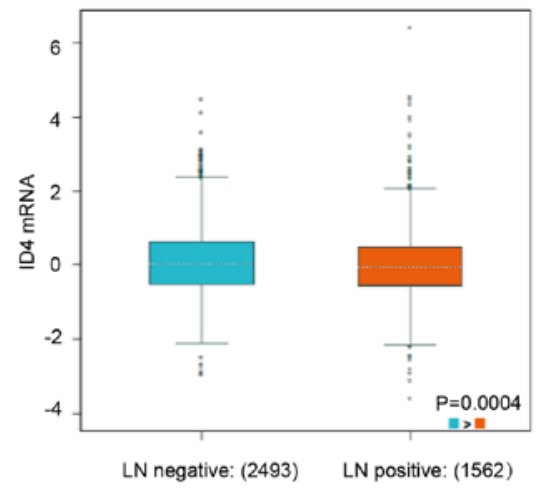

F

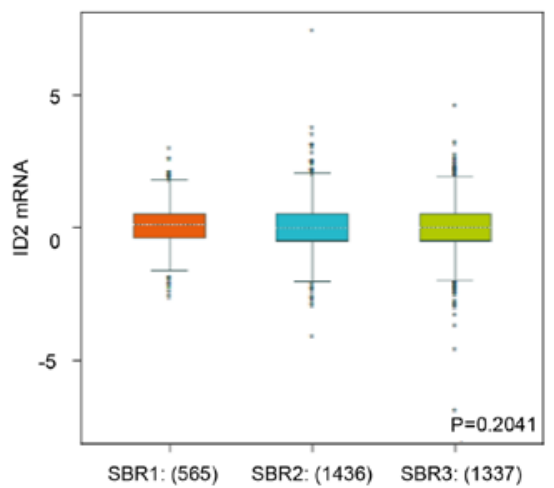

$\mathrm{H}$

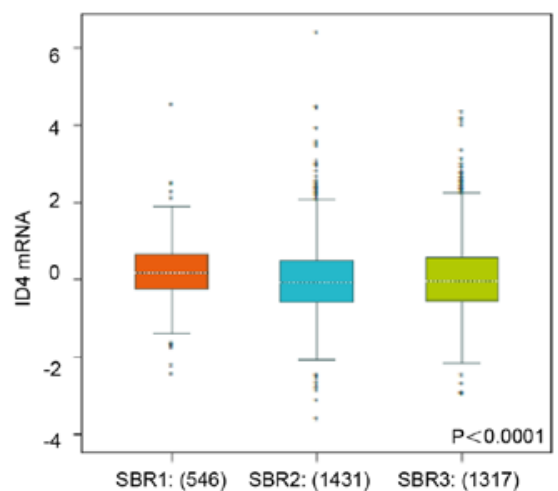

Figure 2. The relationship between mRNA expression of ID family members and lymph node metastasis status as well as SBR grade status. (A-D) The mRNA expression level of ID1-4 in BC patients with different LN status. (E-H) The mRNA expression level of ID1-4 in BC patients with different SBR status. Global significant difference between groups was assessed by Welch's test to generate P-values, along with Dunnett-Tukey-Kramer's tests for pairwise comparison when a global significant difference existed $(\mathrm{P}<0.05)$. SBR, Scarff-Bloom-Richardson.

Increased IDI and ID4 expression is associated with the subgroup with no lymph node metastasis and with lower tumor grades. To further identify the mRNA expression of ID family members in different clinicopathological groups of patients, bc-GenExMiner database analysis was used. Increased ID1
mRNA and ID4 mRNA expression was observed in the negative lymph node metastasis $\mathrm{BC}$ patients (Fig. 2A, $\mathrm{P}=0.0005$; Fig. 2D, $\mathrm{P}=0.0004)$. Nevertheless, no statistically significant difference in ID2 and ID3 mRNA expression was observed between patients with $\mathrm{LN}(+)$ and $\mathrm{LN}(-) \mathrm{BC}$ (Fig. 2B, P=0.9169; 
A

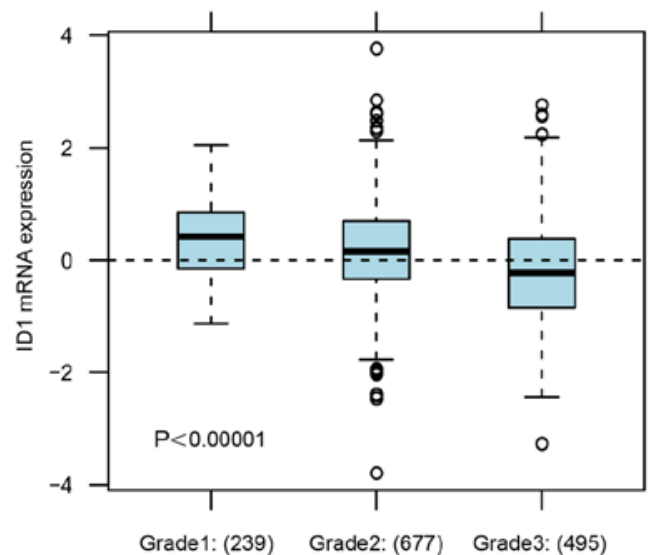

C

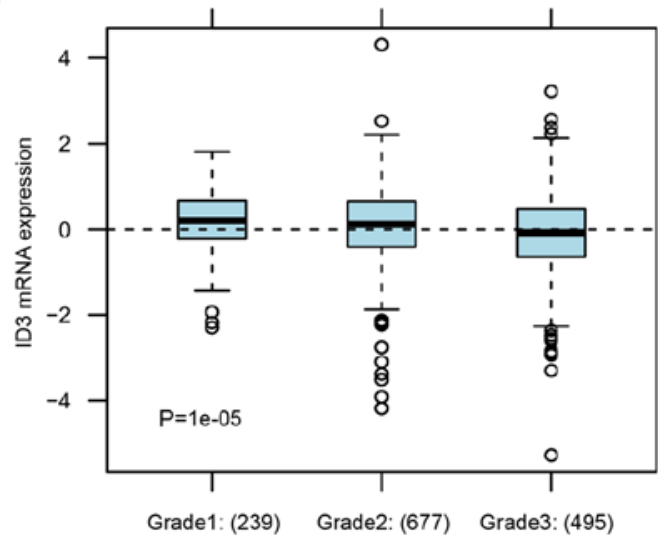

B

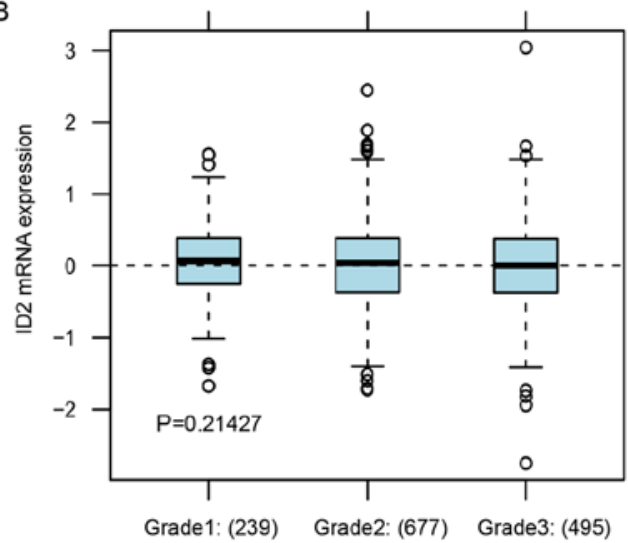

D

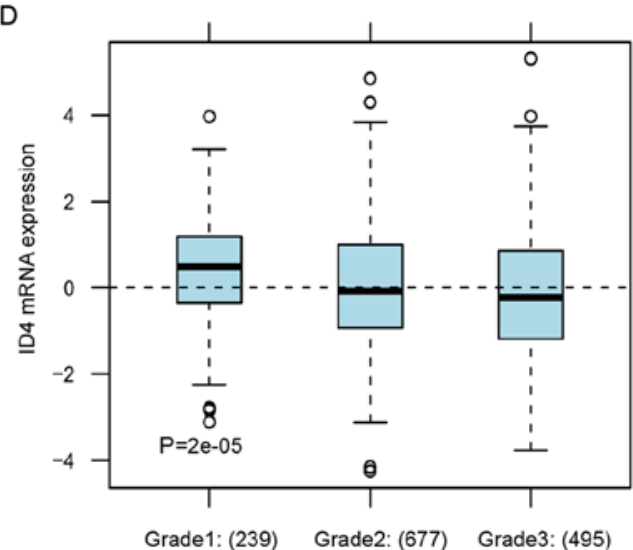

Figure 3. The relationship between gene expression level of ID family members and tumor grade. (A) The mRNA expression level of ID1 in BC patients with different grade status. (B) The mRNA expression level of ID2 in BC patients with different grade status. (C) The mRNA expression level of ID3 in BC patients with different grade status. (D) The mRNA expression level of ID4 in BC patients with different grade status. Global significant difference between groups was assessed to generate $\mathrm{P}$-values and $\mathrm{P}<0.05$ was considered to indicate a statistically significant difference.

Table I. Lower SBR grade status is associated with the enriched mRNA level of ID1.

\begin{tabular}{ll}
\hline Group comparison & P-value $^{\mathrm{a}}$ \\
\hline SBR2<SBR1 & $\mathrm{P}<0.0001$ \\
SBR3 $<$ SBR1 & $\mathrm{P}<0.0001$ \\
SBR3=SBR2 & $\mathrm{P}>0.1000$
\end{tabular}

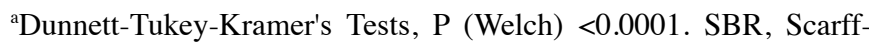
Bloom-Richardson.

Table II. Lower SBR grade is associated with the enriched mRNA level of ID3.

\begin{tabular}{ll} 
Group comparison & P-value \\
\hline SBR3<SBR1 & $\mathrm{P}<0.0001$ \\
SBR3 $<$ SBR2 & $\mathrm{P}<0.0001$ \\
SBR2=SBR1 & $\mathrm{P}>0.1000$ \\
\hline
\end{tabular}

${ }^{\text {aD }}$ unnett-Tukey-Kramer's Tests, P (Welch) $<0.0001$. SBR, ScarffBloom-Richardson.
Table III. Lower SBR grade is associated with the enriched mRNA level of ID4.

\begin{tabular}{lc}
\hline Groups comparison & P-value \\
\hline SBR2 $<$ SBR1 & $\mathrm{P}<0.0001$ \\
SBR3 $<$ SBR1 & $\mathrm{P}<0.0100$ \\
SBR3 $>$ SBR2 & $\mathrm{P}<0.1000$
\end{tabular}

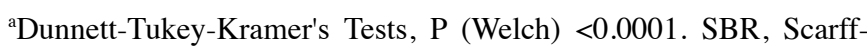
Bloom-Richardson.

Fig. 2C, $\mathrm{P}=0.4145)$. Lower Scarff-Bloom-Richardson (SBR) status grade (30), was associated with a higher mRNA expression level of ID1, ID3 and ID4 (Fig. 2E, P<0.0001; Fig. 2G, $\mathrm{P}<0.0001$; Fig. $2 \mathrm{H}, \mathrm{P}<0.0001)$, but was not associated with the mRNA expression level of ID2 (Fig. 2F, P=0.2041). All the subgroup comparisons are presented in Tables I-III.

Consistently, in $G O B O$ analysis, the lower tumor grade subgroup of $\mathrm{BC}$ patients was associated with increased expression levels ID1, ID3 ID4 (Fig. 3A, P<0.00001; Fig. 3C, $\mathrm{P}=0.00001$; Fig. 3D, $\mathrm{P}=0.00002)$, but was not associated with the mRNA expression level of ID2 (Fig. 3B, $\mathrm{P}=0.21427$ ). 
A

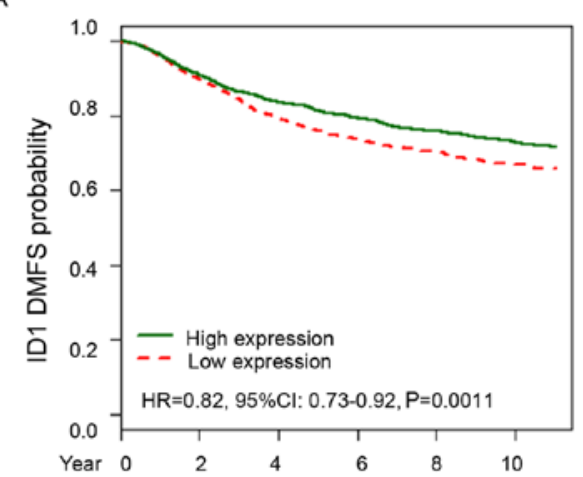

C

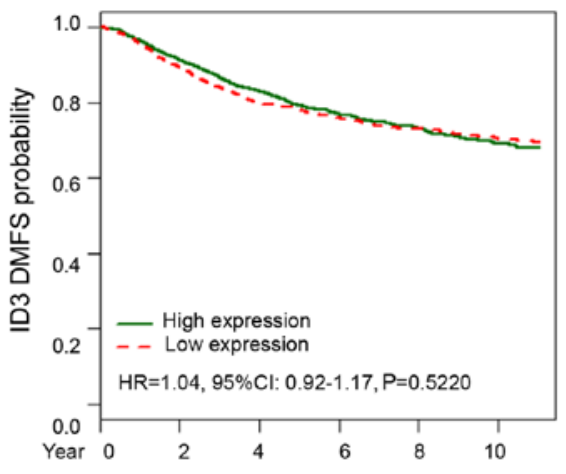

E

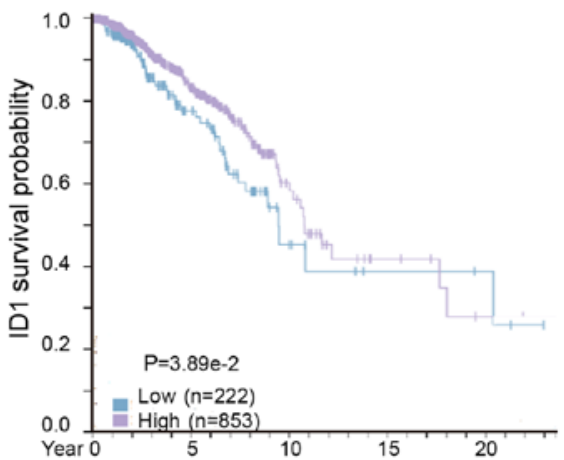

G

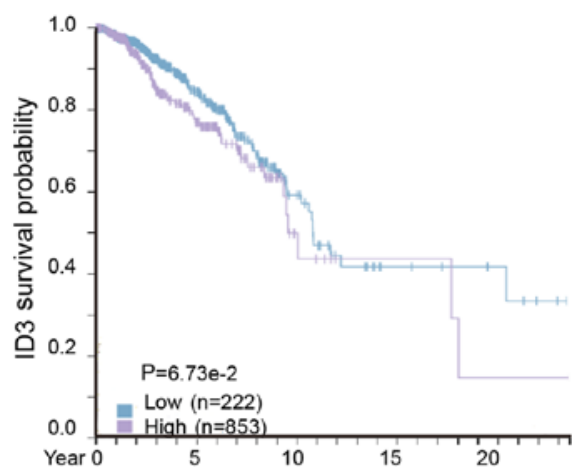

B

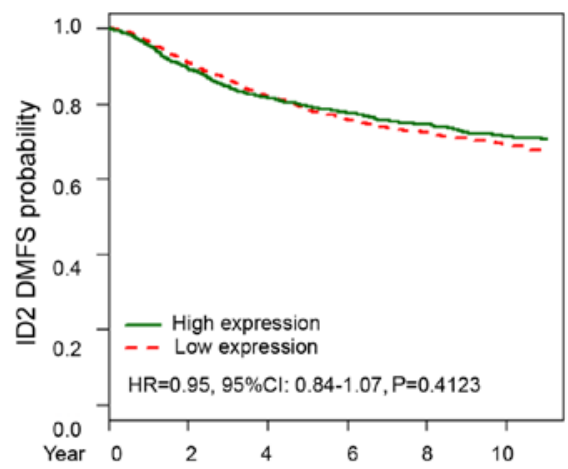

D

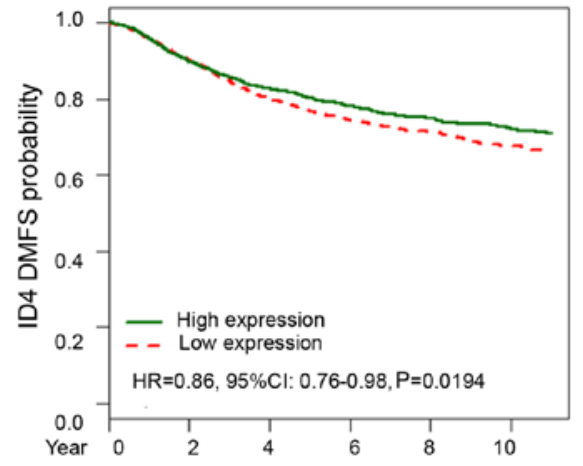

F

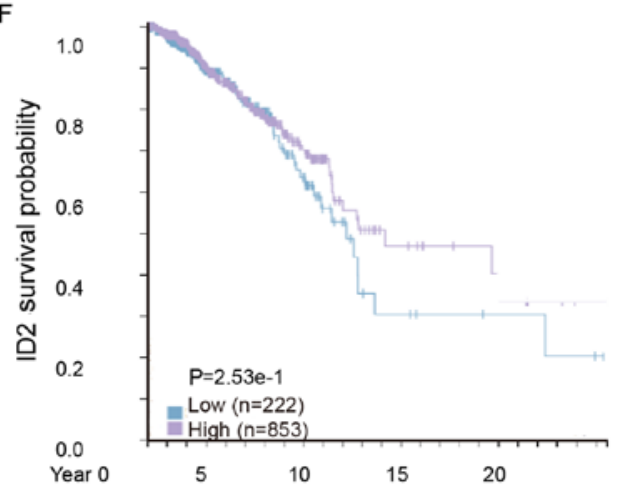

$\mathrm{H}$

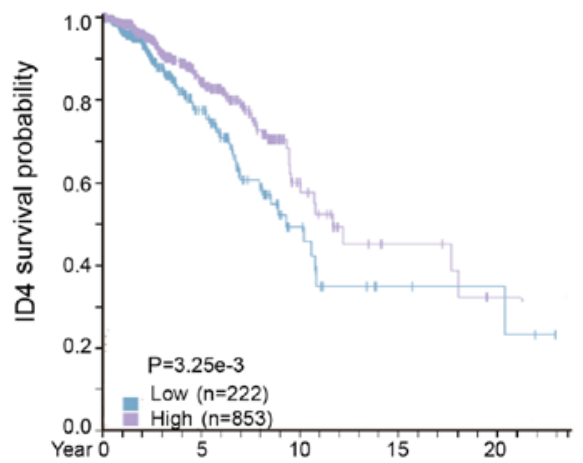

Figure 4. The prognostic values of ID family members in BC. (A-D) Kaplan-Meier metastasis-free survival estimates for ID1-4 mRNA levels. (E-H) Impact of ID1-4 protein level for survival of patients with BC. BC, breast cancer.

These data indicated that increased expression of ID1 and ID4 was associated with the subgroup of BC patients with a low malignant grade and low metastasis potential.

Increased expression of IDI and ID4 predicts an improved survival in patients with $B C$. Subsequently, the distant metastasis prognostic effect of ID family members in BC was analyzed. Analysis from bc-GenExMiner demonstrated that increased ID1 or ID4 mRNA was associated with longer distant metastasis-free survival (DMFS) times in all patients with BC (Fig. 4A, HR=0.82, 95\% CI: 0.73-0.92, $\mathrm{P}=0.0011$; Fig. 4D, HR=0.86, 95\% CI: 0.76-0.98, $\mathrm{P}=0.0194)$. However, 
A

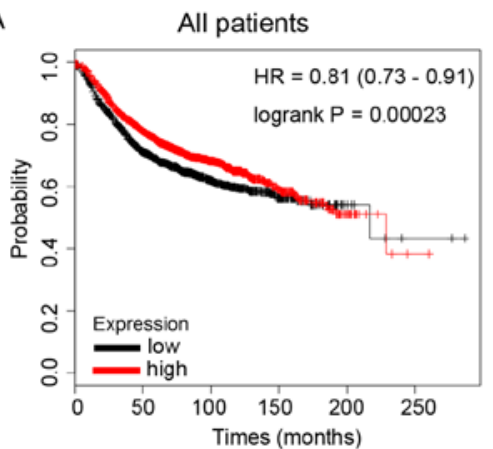

D

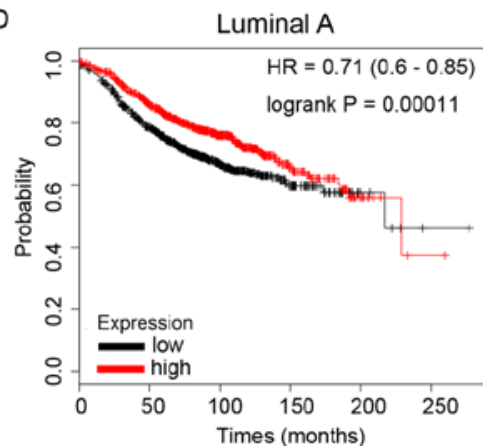

G

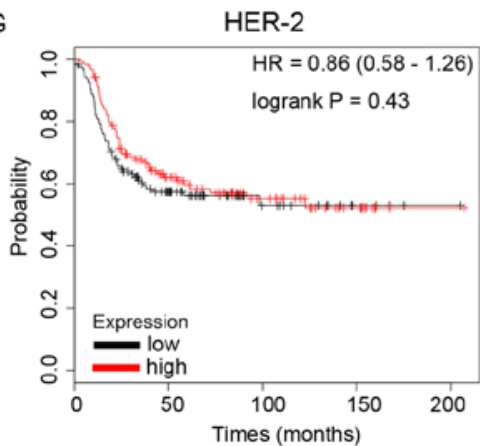

B

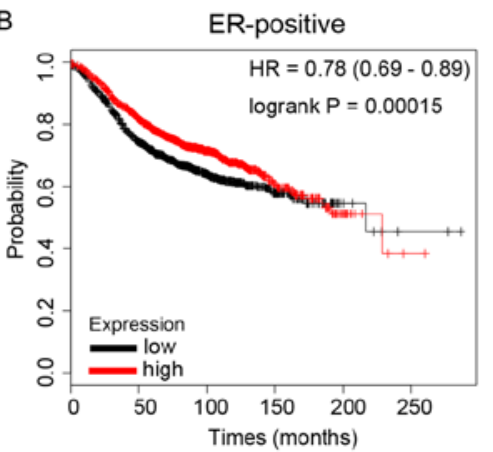

$E$

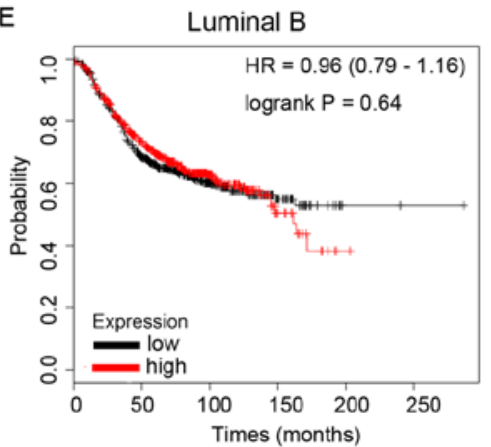

C

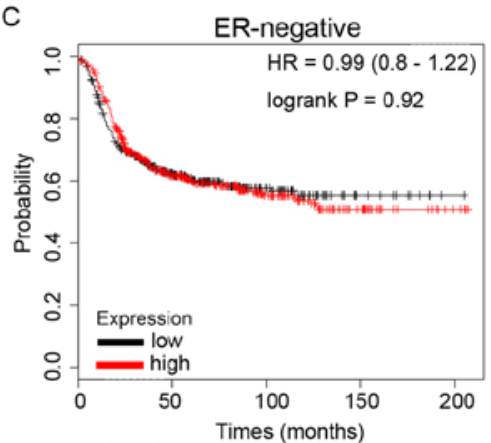

$F$

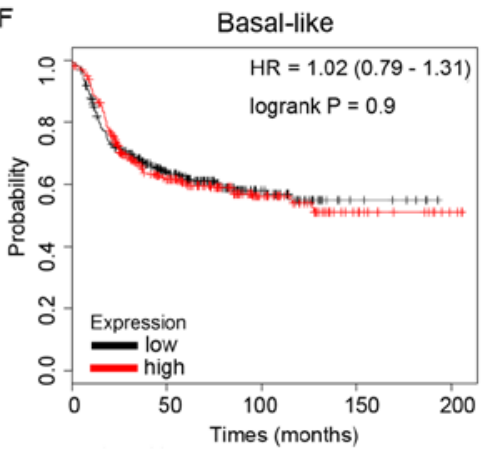

Figure 5. The prognostic values of ID1 in BC. (A) ID1 mRNA level in all BC patients. (B and C) ID1 mRNA level in ER-positive and ER-negative BC patients. (D-G) ID1 mRNA level in different molecular subtypes of BC patients. BC, breast cancer.

ID2 and ID3 mRNA expression levels were not significantly associated with DMFS among all BC patients (Fig. 4B, $\mathrm{HR}=0.95$, 95\% CI: 0.84-1.07, $\mathrm{P}=0.4123$; Fig. 4C, $\mathrm{HR}=1.04$, 95\% CI: $0.92-1.17, \mathrm{P}=0.5220$ ). These results confirmed that higher expression of ID1 and ID4 predicted a lower potential of metastasis and improved DMFS in patients with BC.

Consistently, analysis from The Human Protein Atlas revealed that increased ID1 or ID4 protein expression was associated with improved survival in patients with BC (Fig. 4E, $\mathrm{P}=0.0389$; Fig. 4H, $\mathrm{P}=0.00325)$. However, there was no significant difference in the protein expression levels of ID2 or ID3 in patients with $\mathrm{BC}$ (Fig. 4F, $\mathrm{P}=0.253$; Fig. 4G, $\mathrm{P}=0.0673$ ).

Among the ID family, the expression of ID1 and ID3 have a significant positive correlation in BC (data not shown).

Increased IDI mRNA expression is significantly associated with longer RFS times in patients with BC, particularly in the ER-positive subtypes. The present study then evaluated the prognostic values of ID family members for BC using the KM Plotter database. RFS was analyzed for each gene. It was demonstrated that high ID1 mRNA expression predicted longer RFS times in patients with $\mathrm{BC}$ (Fig. $5 \mathrm{~A}, \mathrm{HR}=0.81$, $\mathrm{P}=0.00023$ ). In particular, sub-analysis revealed that elevated ID1 mRNA expression was associated with longer RFS times in the ER-positive BC subgroup of patients (Fig. 5B, HR=0.78, $\mathrm{P}=0.00015)$, but not in the ER-negative BC subgroup of patients (Fig. 5C, $\mathrm{HR}=0.99, \mathrm{P}=0.92$ ).

In addition, increased ID1 mRNA expression was significantly associated with longer RFS times in BC patients with special molecular subtype Luminal A tumors (Fig. 5D, $\mathrm{HR}=0.71, \mathrm{P}=0.00011$ ), but not in other molecular subtypes, including Luminal B (Fig. 5E, HR=0.96, P=0.64), HER-2 type (Fig. 5G, $\mathrm{HR}=0.86, \mathrm{P}=0.43$ ) and Basal-like (Fig. 5F, $\mathrm{HR}=1.02, \mathrm{P}=0.9)$. These data demonstrated that ID1-overexpression was associated with longer survival times in patients with BC, particularly in the ER-positive and Luminal A subtype subgroups.

Increased ID4 predicts improved survival in patients with $B C$, particularly in the hormone receptor-positive patients and the subgroup of patients treated with endocrine therapy. RFS analysis of ID4 from the KM Plotter database revealed that 
A

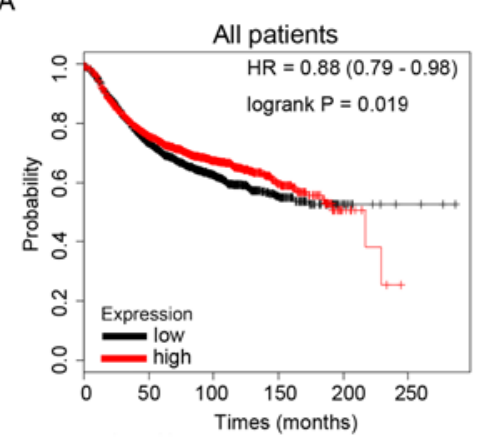

D

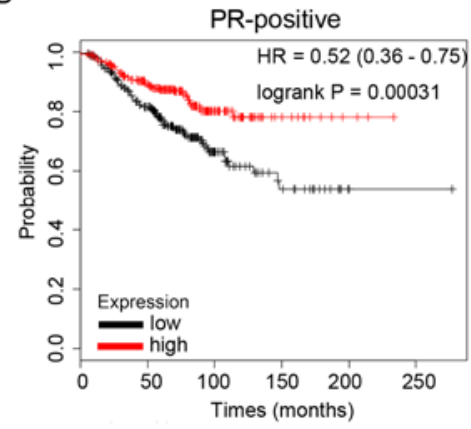

G
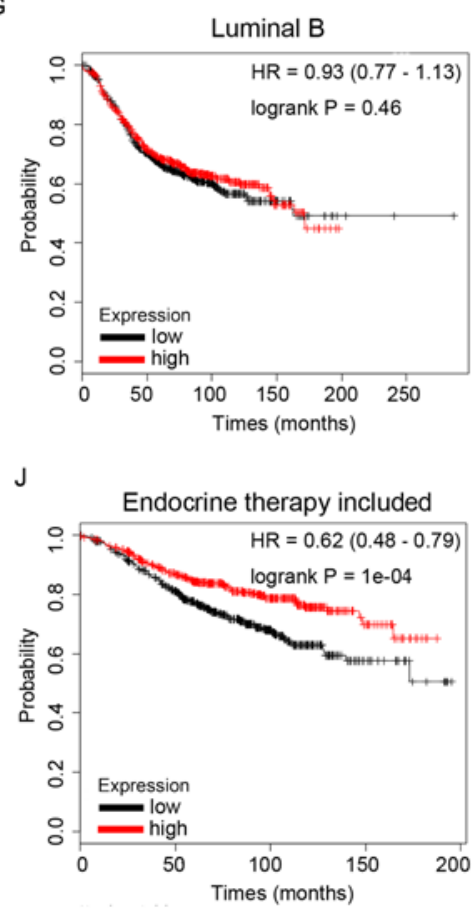

B

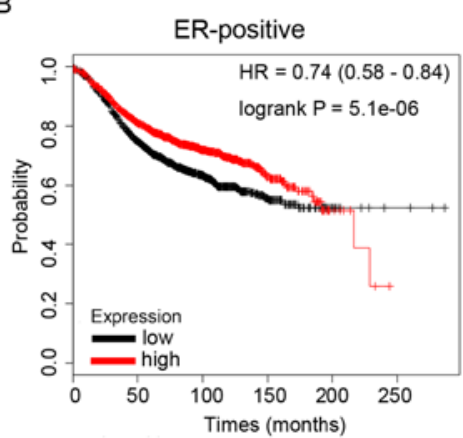

E

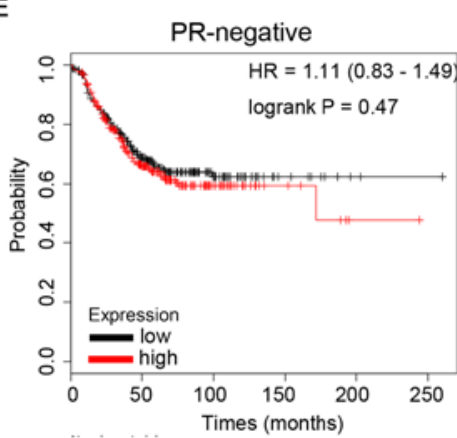

$\mathrm{H}$

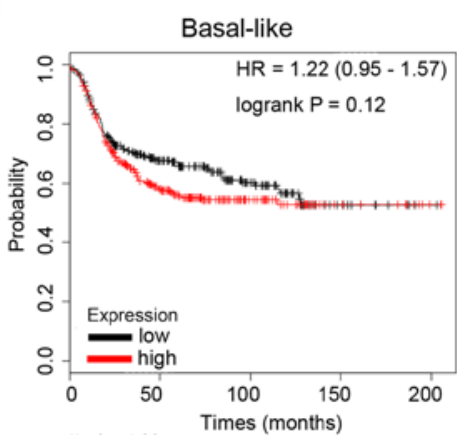

$\mathrm{K}$

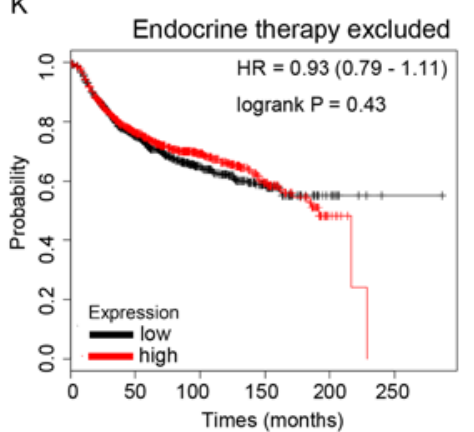

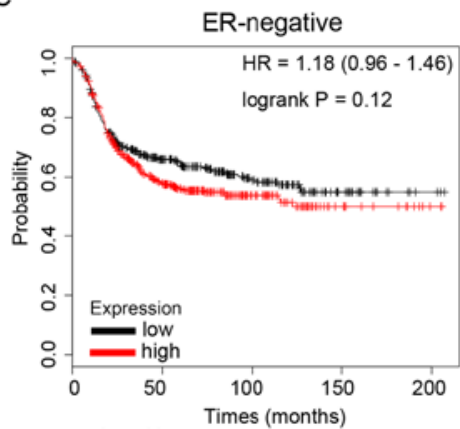

F
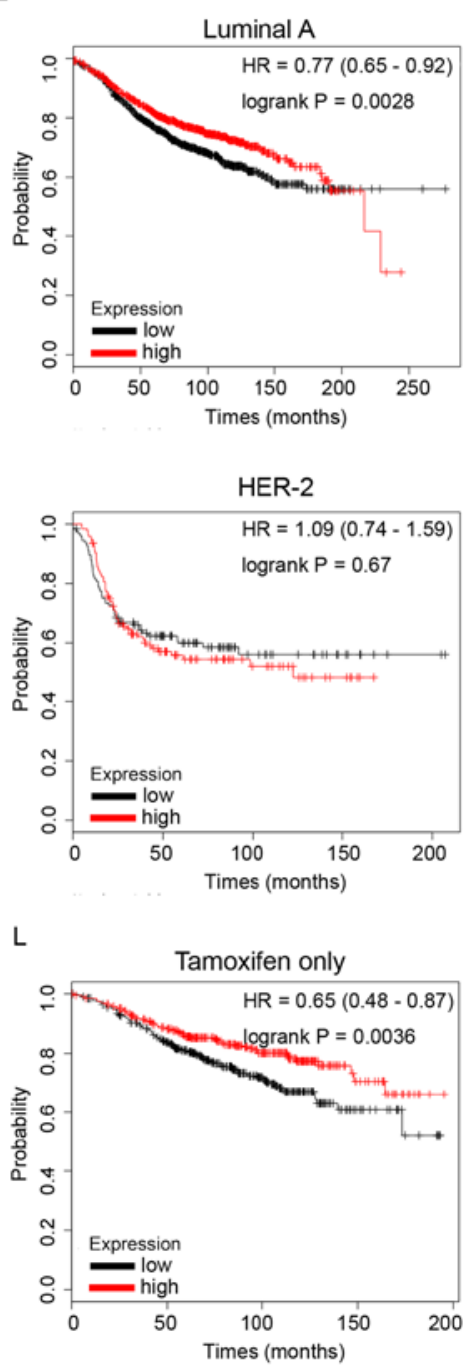

Figure 6. The prognostic values of ID4 in BC. (A) ID4 mRNA level in all BC patients. (B and C) ID4 mRNA level in ER-positive and ER-negative BC patients. (D and E) ID4 mRNA level in PR-positive and PR-negative BC patients. (F-I) ID4 mRNA level in different molecular subtypes of BC patients. (J and K) ID4 mRNA level in BC patients with endocrine therapy included or excluded. (L) ID4 mRNA level in BC patients who received tamoxifen for endocrine therapy only. BC, breast cancer.

high expression of ID4 mRNA was associated with improved RFS in patients with $\mathrm{BC}$ (Fig. 6A, HR=0.88, $\mathrm{P}=1.9 \mathrm{e}-2$ ). Furthermore, high mRNA expression of ID4 predicted longer survival times in patients with ER-positive (Fig. 6B, $\mathrm{HR}=0.74$, $\mathrm{P}=5.1 \mathrm{e}-6$ ) and PR-positive (Fig. 6D, $\mathrm{HR}=0.52, \mathrm{P}=3.1 \mathrm{e}-4$ ) disease. However, no statistical significance was observed in the groups of ER-negative (Fig. $6 \mathrm{C}, \mathrm{HR}=1.18, \mathrm{P}=0.12$ ) or PR-negative (Fig. 6E, HR=1.11, $\mathrm{P}=0.47$ ) patients. These data revealed that increased expression of ID4 predicted longer survival times in patients with BC, particularly in the hormone receptor-positive subgroup of patients.

Furthermore, subgroup analysis revealed that increased ID4 mRNA expression was significantly associated with improved RFS in BC patients with Luminal A molecular subtype tumors (Fig. 6F, HR=0.77, $\mathrm{P}=2.8 \mathrm{e}-3$ ), but not in other molecular subtypes, including Luminal B (Fig. 6G, HR=0.93, $\mathrm{P}=0.46$ ), Basal-like (Fig. 6H, HR=1.22, $\mathrm{P}=0.12$ ) and HER-2 type (Fig. 6I, HR=1.09, $\mathrm{P}=0.67$ ). 
Additionally, higher mRNA expression of ID4 was significantly associated with longer RFS times in patients with $\mathrm{BC}$ who had received endocrine therapy (Fig. 6J, HR=0.62, $\mathrm{P}=1 \mathrm{e}-4)$, but not in the group that excludes endocrine therapy (Fig. 6K, HR=0.93, $\mathrm{P}=0.43$ ), indicating a potential role of ID4 in endocrine therapy sensitivity in BC. Notably, the results of the present study also revealed that high mRNA expression of ID4 was associated with longer RFS times in patients with $\mathrm{BC}$ who had received tamoxifen for endocrine therapy only (Fig. 6L, HR=0.65, P=3.6e-3), indicating that ID4 may contribute toward tamoxifen therapy sensitivity in BC.

\section{Discussion}

Over recent decades, key molecular signatures associated with BC, including ER, PR and HER-2, have been identified and well-characterized (31). Emerging evidence has continued to identify novel targets and signaling pathways, including PARP, CDK4/6 and PI3K/Akt/mTOR, which significantly contribute toward the pathogenesis and development of $\mathrm{BC}$, leading to a paradigm shift in the treatment of $\mathrm{BC}$ (32).

ID family members are pivotal modulatory proteins that have been recognized to be downstream targets of a number of oncogenic pathways, making them attractive targets for the treatment of cancer $(4,5,33)$. However, there are significant contradictions in the specific roles of different IDs in BC development (34).

In the present study, analysis of Oncomine, bc-Gen ExMiner, The Human Protein Atlas and Kaplan-Meier plotter, was used to systemically depict the expression profiles of individual IDs in BC, revealing that the IDs exhibited marked differences in mRNA expression between breast tumor and normal tissues. The results indicated that the mRNA expression level of ID2 was significantly higher in BC than in normal tissues, while the mRNA expression levels of ID1, ID3 and ID4 were significantly lower in BC tissues than in normal tissues. Wazir et al (35) reported that increased expression of ID1 in BC was correlated with disease severity and predicted a poor survival outcome. Nonetheless, the present study revealed contradictory results in the analysis of ID1 expression in human $\mathrm{BC}$, which may be primarily attributed toward discrepancies in detection methods for mRNA and protein among different investigators.

IDs are capable of promoting the tumorigenesis of $\mathrm{BC}$ by suppressing cell differentiation, activating proliferation and promoting tumor development (12). However, individual IDs may serve diverse roles in this process. Increased ID1 and ID4 expression was associated with the subgroup without lymph node metastasis and a lower tumor grade. The results indicated that ID1 and ID4 may serve suppressive roles in the development of BC.

It has been reported that IDs are important driving forces involving distant metastasis of a variety of cancer types, including BC $(36,37)$. Gumireddy et al (38) demonstrated that ID1 facilitated the spreading of $\mathrm{BC}$ via regulation of S100A9 expression. However, following assessment of the distant metastasis prognostic effect of ID family members in BC through analysis of the bc-GenExMiner database, it was revealed that increased ID1 or ID4 mRNA expression was associated with longer DMFS times in all patients with BC.
The results demonstrated that increased ID1 mRNA expression was significantly associated with longer RFS times in patients with BC, particularly in those with ER-positive and Luminal A subtype tumors. Although the majority of studies have demonstrated that high ID1 expression was generally an adverse prognostic indicator (35), the results have not been entirely consistent. Cheng et al (39) reported a paradoxical result that increased ID1 expression predicts a favorable survival outcome in patients with lung cancer that has been surgically treated, followed by adjuvant paclitaxel plus cisplatin chemotherapy, and this distinct role of ID1 possibly stems from the ID1-dependence of NSCLC cells for survival, thereby rendering the cancer cells to be more sensitive to a specific chemotherapy regimen. The present study also demonstrated that increased ID4 expression was a favorable prognostic factor in patients with BC. Furthermore, it was revealed that increased ID4 expression predicted improved survival in the subset of patients with hormone receptor-positive tumors, as well as the subgroup of patients treated with endocrine therapy. These results were consistent with those of a study undertaken by Zhang et al (40), which reported that hypomethylation of ID4 may act as a critical biomarker for identifying acquired tamoxifen resistance in BC.

Another study undertaken by Patel et al (41) suggested that ID4 may serve a suppressive role in prostate cancer, and that its loss facilitates CRPC through constitutive activation of the androgen receptor. The possible mechanism of this is that ID4 acts as a suppressor of ID-1, -2 and -3 , and stimulates transcription (42). Therefore, we hypothesized that ID4 may serve an essential role in the sensitivity of endocrine therapy.

In summary, the IDs exhibited diverse expression profiles between $\mathrm{BC}$ tissues and normal breast tissues. Notably, the results indicated that increased ID1 and ID4 expression was associated with low pathological grades of $\mathrm{BC}$ and predicted an improved survival outcome in patients with distinct subtypes of BC. Future in-depth studies are warranted to elucidate the exact functions of ID1 and ID4 in oncogenesis and the progression of $\mathrm{BC}$, which may provide further evidence that ID1 and ID4 could be critical prognostic indicators and promising therapeutic targets in $\mathrm{BC}$. However, the in silico analyses are limited; for example, the data is limited to one dataset (Affymetrix arrays-based) and RNA-Seq data (TCGA) or other array platforms (Illumina in the METABRIC) are not taken into consideration. Nonetheless, the results of the present study indicated that IDs were potential prognostic indicators in $\mathrm{BC}$ and further study on the values of IDs in the pathogenesis and development of $\mathrm{BC}$ is warranted.

\section{Acknowledgements}

We are grateful to Dr Pi Guo for critically reading the manuscript. We also thank Dr Yin-Sheng Xiao for advice or technical assistance in the TCGA data analysis.

\section{Funding}

The present study was partly supported by The Natural Science Foundation of Guangdong Province, China (no. 2015A030313429), The Youth Innovative Talent Project 
of Colleges and Universities in Guangdong Province, China (nos. 2016KQNCX051 and 2017KQNCX073).

\section{Availability of data and materials}

The datasets used during the present study are available from the corresponding author upon reasonable request.

\section{Authors' contributions}

HYL designed the study. YHY, SMS and WQL prepared the figures and tables. XFL and CFC analyzed and interpreted the data. XLZ and DZ drafted the manuscript. All authors read and approved the manuscript and agree to be accountable for all aspects of the research in ensuring that the accuracy or integrity of any part of the work are appropriately investigated and resolved.

\section{Ethics approval and consent to participate}

Not applicable.

\section{Patient consent for publication}

Not applicable.

\section{Competing interests}

The authors declare that they have no competing interests.

\section{References}

1. Yokota $\mathrm{Y}$ and Mori S: Role of Id family proteins in growth control. J Cell Physiol 190: 21-28, 2002.

2. Patel D, Morton DJ, Carey J, Havrda MC and Chaudhary J: Inhibitor of differentiation 4 (ID4): From development to cancer. Biochim Biophys Acta 1855: 92-103, 2015.

3. Kamalian L, Gosney JR, Forootan SS, Foster CS, Bao ZZ, Beesley $\mathrm{C}$ and $\mathrm{Ke} \mathrm{Y}$ : Increased expression of Id family proteins in small cell lung cancer and its prognostic significance. Clin Cancer Res 14: 2318-2325, 2008.

4. Cruz-Rodriguez N, Combita AL, Enciso LJ, Quijano SM, Pinzon PL, Lozano OC, Castillo JS, Li L, Bareño J, Cardozo C, et al: High expression of ID family and IGJ genes signature as predictor of low induction treatment response and worst survival in adult Hispanic patients with B-acute lymphoblastic leukemia. J Exp Clin Cancer Res 35: 64, 2016.

5. Perk J, Iavarone A and Benezra R: Id family of helix-loop-helix proteins in cancer. Nat Rev Cancer 5: 603-614, 2005.

6. O'Brien CA, Kreso A, Ryan P, Hermans KG, Gibson L, Wang Y, Tsatsanis A, Gallinger S and Dick JE: ID1 and ID3 regulate the self-renewal capacity of human colon cancer-initiating cells through p21. Cancer Cell 21: 777-792, 2012.

7. Ren Y, Cheung HW, von Maltzhan G, Agrawal A, Cowley GS, Weir BA, Boehm JS, Tamayo P, Karst AM, Liu JF, et al: Targeted tumor-penetrating siRNA nanocomplexes for credentialing the ovarian cancer oncogene ID4. Sci Transl Med 4: 147ra112, 2012.

8. Zhao TF, Jia HZ, Zhang ZZ, Zhao XS, Zou YF, Zhang W, Wan J and Chen XF: LncRNA H19 regulates ID2 expression through competitive binding to hsa-miR-19a/b in acute myelocytic leukemia. Mol Med Rep 16: 3687-3693, 2017.

9. Korang-Yeboah M, Patel D, Morton D, Sharma P, Gorantla Y, Joshi J, Nagappan P, Pallaniappan R and Chaudhary J: Intra-tumoral delivery of functional ID4 protein via PCL/ maltodextrin nano-particle inhibits prostate cancer growth. Oncotarget 7: 68072-68085, 2016.

10. Minn AJ, Gupta GP, Siegel PM, Bos PD, Shu W, Giri DD, Viale A, Olshen AB, Gerald WL and Massagué J: Genes that mediate breast cancer metastasis to lung. Nature 436: 518-524, 2005.
11. Gupta GP, Perk J, Acharyya S, de Candia P, Mittal V, Todorova-Manova K, Gerald WL, Brogi E, Benezra R and Massagué J: ID genes mediate tumor reinitiation during breast cancer lung metastasis. Proc Natl Acad Sci USA 104: 19506-19511, 2007.

12. Lasorella A, Benezra R and Iavarone A: The ID proteins: Master regulators of cancer stem cells and tumour aggressiveness. Nat Rev Cancer 14: 77-91, 2014.

13. Sikder HA, Devlin MK, Dunlap S, Ryu B and Alani RM: Id proteins in cell growth and tumorigenesis. Cancer Cell 3: 525-530, 2003.

14. Sun XH, Copeland NG, Jenkins NA and Baltimore D: Id proteins Id1 and Id2 selectively inhibit DNA binding by one class of helix-loop-helix proteins. Mol Cell Biol 11: 5603-5611, 1991.

15. Rollin J, Bléchet C, Régina S, Tenenhaus A, Guyétant S and Gidrol X: The intracellular localization of ID2 expression has a predictive value in non small cell lung cancer. PLoS One 4: e4158, 2009.

16. Chen XS, Zhang YH, Cai QY and Yao ZX: ID2: A negative transcription factor regulating oligodendroglia differentiation. J Neurosci Res 90: 925-932, 2012.

17. Kleeff J, Ishiwata T, Friess H, Buchler MW, Israel MA and Korc M: The helix-loop-helix protein Id2 is overexpressed in human pancreatic cancer. Cancer Res 58: 3769-3772, 1998.

18. Li K, Yao L, Chen L, Cao ZG, Yu SJ, Kuang XY, Hu X and Shao ZM: ID2 predicts poor prognosis in breast cancer, especially in triple-negative breast cancer, and inhibits E-cadherin expression. Onco Targets Ther 7: 1083-1094, 2014.

19. Itahana Y, Singh J, Sumida T, Coppe JP, Parrinello S, Bennington JL and Desprez PY: Role of Id-2 in the maintenance of a differentiated and noninvasive phenotype in breast cancer cells. Cancer Res 63: 7098-7105, 2003.

20. Stighall M, Manetopoulos C, Axelson H and Landberg G: High ID2 protein expression correlates with a favourable prognosis in patients with primary breast cancer and reduces cellular invasiveness of breast cancer cells. Int J Cancer 115: 403-411, 2005.

21. Kowanetz M, Valcourt U, Bergström R, Heldin CH and Moustakas A: Id 2 and Id 3 define the potency of cell proliferation and differentiation responses to transforming growth factor beta and bone morphogenetic protein. Mol Cell Biol 24: 4241-4254, 2004.

22. Wen YH, Ho A, Patil S, Akram M, Catalano J, Eaton A, Norton L, Benezra R and Brogi E: Id4 protein is highly expressed in triple-negative breast carcinomas: Possible implications for BRCA1 downregulation. Breast Cancer Res Treat 135: 93-102, 2012.

23. Thike AA, Tan PH, Ikeda M and Iqbal J: Increased ID4 expression, accompanied by mutant p53 accumulation and loss of BRCA $1 / 2$ proteins in triple-negative breast cancer, adversely affects survival. Histopathology 68: 702-712, 2016.

24. Lin HY, Zeng, Liang YK, Wei XL and Chen CF: GATA3 and TRPS1 are distinct biomarkers and prognostic factors in breast cancer: Database mining for GATA family members in malignancies. Oncotarget 8: 34750-34761, 2017.

25. Jezequel P, Frenel JS, Campion L, Guérin-Charbonnel C, Gouraud W, Ricolleau G and Campone M: bc-GenExMiner 3.0: New mining module computes breast cancer gene expression correlation analyses. Database 2013: bas060, 2013.

26. Jezequel P, Campone M, Gouraud W, Guérin-Charbonnel C Leux C, Ricolleau G and Campion L: bc-GenExMiner: An easy-to-use online platform for gene prognostic analyses in breast cancer. Breast Cancer Res Treat 131: 765-775, 2012.

27. Thul PJ, Akesson L, Wiking M, Mahdessian D, Geladaki A, Ait Blal H, Alm T, Asplund A, Björk L, Breckels LM, et al: A subcellular map of the human proteome. Science 356: pii: eaal3321, 2017.

28. Uhlen M, Fagerberg L, Hallstrom BM, Lindskog C, Oksvold P, Mardinoglu A, Sivertsson Å, Kampf C, Sjöstedt E, Asplund A, et al: Proteomics. Tissue-based map of the human proteome. Science 347: 1260419, 2015.

29. Gyorffy B, Lanczky A, Eklund AC, Denkert C, Budczies J, Li Q and Szallasi Z: An online survival analysis tool to rapidly assess the effect of 22,277 genes on breast cancer prognosis using microarray data of 1,809 patients. Breast Cancer Res Treat 123: 725-731, 2010.

30. Curtit E, Pivot X, Henriques J, Paget-Bailly S, Fumoleau P, Rios M, Bonnefoi H, Bachelot T, Soulié P, Jouannaud C, et al: Assessment of the prognostic role of a 94-single nucleotide polymorphisms risk score in early breast cancer in the SIGNAL/PHARE prospective cohort: No correlation with clinico-pathological characteristics and outcomes. Breast Cancer Res 19: 98, 2017. 
31. Fragomeni SM, Sciallis A and Jeruss JS: Molecular subtypes and local-regional control of breast cancer. Surg Oncol Clin N Am 27: 95-120, 2018

32. Pawlik TM: Innovation in the diagnosis and management of breast cancer. Surg Oncol Clin N Am 27: xiii-xiv, 2018.

33. Murad JM, Place CS, Ran C, Hekmatyar SK, Watson NP, Kauppinen RA and Israel MA: Inhibitor of DNA binding 4 (ID4) regulation of adipocyte differentiation and adipose tissue formation in mice. J Biol Chem 285: 24164-24173, 2010.

34. Yang HY, Liu HL, Ke J, Wu H, Zhu H, Liu JR, Liu LX and Jiang HC: Expression and prognostic value of Id protein family in human breast carcinoma. Oncol Rep 23: 321-328, 2010.

35. Wazir U, Jiang WG, Sharma AK, Newbold RF and Mokbel K: The mRNA expression of inhibitors of DNA binding-1 and -2 is associated with advanced tumour stage and adverse clinical outcome in human breast cancer. Anticancer Res 33: 2179-2183, 2013.

36. Umetani N, Mori T, Koyanagi K, Shinozaki M, Kim J, Giuliano AE and Hoon DS: Aberrant hypermethylation of ID4 gene promoter region increases risk of lymph node metastasis in T1 breast cancer. Oncogene 24: 4721-4727, 2005.

37. Li B, Tsao SW, Li YY, Wang X, Ling MT, Wong YC, He QY and Cheung AL: Id-1 promotes tumorigenicity and metastasis of human esophageal cancer cells through activation of PI3K/AKT signaling pathway. Int J Cancer 125: 2576-2585, 2009.

38. Gumireddy K, Li A, Kossenkov AV, Cai KQ, Liu Q, Yan J, Xu H, Showe L, Zhang L and Huang Q: ID1 promotes breast cancer metastasis by S100A9 regulation. Mol Cancer Res 12: 1334-1343, 2014.
39. Cheng YJ, Lee YC, Chiu WC, Tsai JW, Su YH, Hung AC, Chang PC, Huang CJ, Chai CY and Yuan SS: High Id1 expression, a generally negative prognostic factor, paradoxically predicts a favorable prognosis for adjuvant paclitaxel plus cisplatin therapy in surgically treated lung cancer patients. Oncotarget 5: 11564-11575, 2014

40. Zhang Y, Zhang B, Fang J and Cao X: Hypomethylation of DNA-binding inhibitor 4 serves as a potential biomarker in distinguishing acquired tamoxifen-refractory breast cancer. Int J Clin Exp Pathol 8: 9500-9505, 2015.

41. Patel D, Knowell AE, Korang-Yeboah M, Sharma P, Joshi J, Glymph S, Chinaranagari S, Nagappan P, Palaniappan R, Bowen NJ and Chaudhary J: Inhibitor of differentiation 4 (ID4) inactivation promotes de novo steroidogenesis and castration-resistant prostate cancer. Mol Endocrinol 28: 1239-1253, 2014.

42. Sharma $\mathrm{P}$, Chinaranagari $\mathrm{S}$ and Chaudhary $\mathrm{J}$ : Inhibitor of differentiation 4 (ID4) acts as an inhibitor of ID $-1,-2$ and -3 and promotes basic helix loop helix (bHLH) E47 DNA binding and transcriptional activity. Biochimie 112: 139-150, 2015.

This work is licensed under a Creative Commons Attribution-NonCommercial-NoDerivatives 4.0 International (CC BY-NC-ND 4.0) License. 